\title{
The development of seasonal structural fronts in the Baltic Sea after winters of varying severity
}

\author{
Natalia Demchenko ${ }^{1, *}$, Irina Chubarenko ${ }^{1}$, Seppo Kaitala ${ }^{2}$ \\ ${ }^{1}$ P.P.Shirshov Institute of Oceanology of Russian Academy of Sciences, Atlantic branch, Prospect Mira 1, 236022 Kaliningrad, \\ Russia \\ ${ }^{2}$ Finnish Environment Institute (SYKE), Mechelininkatu 34a, PO BOX 140, 00251 Helsinki, Finland
}

\begin{abstract}
The manifestation in the Baltic Sea of a seasonal, structural, thermally-induced front (a direct analogue of the lacustrine thermal bar) and its specific features after winters of different severity are examined. Analysis of long-term, spring-period, monthly mean SST data reveals that surface water temperatures first exceed the (salinity-dependent) temperature of maximum density (Tmd) in the southern part of the Baltic Sea. This phenomenon advances northwards at a speed of about 11 to $16 \mathrm{~km} \mathrm{~d}^{-1}$, traversing the breadth of the sea within 8 to $10 \mathrm{wk}$. Surface temperature measurements across the Tmd-isotherm demonstrate that after the severe winter of 2002-2003 the frontal zone was highly pronounced, with a horizontal temperature gradient 10 to 100 times as large as the long-term monthly mean equivalent. Although the horizontal gradient was smaller after the mild winter of 20062007, it was still 10 times as large as the long-term monthly mean gradient. A clear correlation of thermal front advancement with biological parameters is revealed: an area of elevated chlorophyll $a$ (about $200 \mathrm{~km}$ in width) associated with the Tmd was observed after severe winters, with the characteristic life-time of this zone 1 mo longer than that occurring after mild winters.
\end{abstract}

KEY WORDS: Temperature of maximum density $\cdot$ Thermal bar $\cdot$ Mixing $\cdot$ Baltic Sea

\section{INTRODUCTION}

The investigation of mixing mechanisms in lakes and inland seas is an important part of hydro-physical research, with particular attention paid to specific features of frontal zones. The commonly accepted definition of a frontal zone of any parameter (e.g. water temperature) is based on a comparison between the observed horizontal gradient and a large-scale mean gradient in the given area (e.g. Fedorov 1983). If the observed gradients are more than an order of magnitude larger than their large-scale mean equivalent, the area in question can then be considered a frontal zone. Fronts associated with the change in water temperature of a basin across the temperature of maximum density ( $\mathrm{Tmd} ; 3.98^{\circ} \mathrm{C}$ for fresh water) in spring and autumn are known in limnology as thermal bars. Discovered for the first time in autumn 1899 in Lake Geneva by F.A. Forel (Forel 1901), thermal bars have been widely investigated ever since, including in the Great Lakes of America (Rodgers 1966) and in many Russian lakes such as Ladoga, Onega and Baikal (Shimaraev 1977, Tikhomirov 1982).

In order to clearly present the mechanics of mixing in the presence of the Tmd, it is first necessary to consider the principal current structure in the shallow part of a freshwater basin during spring heating (Fig. 1). As soon as the general heat balance of the surface layer becomes positive, the formerly inverse vertical thermal stratification of the basin changes, with vertical convective mixing commencing with the formation and growth of the upper quasi-homogeneous layer. An increase in density is observed due to the influx of warmer water characterized by temperatures higher than that of the quasi-homogeneous layer, but still below the Tmd. Horizontal exchange between shallow and deep water takes place in the form of a densitydriven downslope cascade. Further density increases 
are associated with the existence of warm water in deep layers. In shallow regions, where vertical convection reaches the bottom, heating proceeds more rapidly. In regions of equal heat removal, shallow water is warmed while in deeper parts of the same water column vertical mixing leads to the introduction of new water (and thus increases the thickness of the quasihomogeneous layer). As a result, large seasonal horizontal temperature/density gradients form between shallow and deep parts of the basin. With further heating, the density of the surface waters decreases, vertical convection stops and direct vertical stratification is established. As heating continues, this area extends further towards the deeper parts of the basin. During an initial time period (ca. 4 to $8 \mathrm{~h}$ on the basis of field observations from Lake Ladoga; Naumenko 1992), water currents are not yet developed and the Tmdisotherm advances only due to heat supply from the atmosphere. This is known as the 'slow phase' of thermal bar development (Kreiman 1989). During the later stage or 'fast phase' of thermal bar development (Kreiman 1989), the location of the Tmd-isotherm at the surface is associated with the leading edge of the subsurface jet (with $\mathrm{T}>\mathrm{Tmd}$ ), which propagates horizontally above a layer where $\mathrm{T}<\mathrm{Tmd}$ (Chubarenko \& Demchenko 2008: see Fig. 1a).

Many characteristic features of spring thermal bars in lakes have been determined by direct field observation. For instance, field measurements of Lake Ladoga (Rumiantsev \& Drabkova 2002) have demonstrated (1) the occurrence of an obvious temperature jump in the vicinity of the Tmd, the value of which depends on external atmospheric conditions (such as severity of winter); (2) that typical temperature gradients in the frontal zone are in the order of $10^{-4 \circ} \mathrm{C} \mathrm{m}^{-1}$ (Naumenko 1989); and (3) the occurrence of significant horizontal velocity gradients in the frontal zone (Naumenko 1992). Typical propagation speeds of the thermal bar front in lakes during spring and autumn periods have been measured at around 2.5 to $4 \mathrm{~km} \mathrm{~d}^{-1}$ (Tikhomirov 1982, Naumenko \& Karetnikov 1998).

Such fronts can also be formed in brackish waters ( $\mathrm{S}<24.7 \mathrm{psu})$, since the Tmd is above the freezing point of waters with salinities below $24.7 \mathrm{psu}$, but below the freezing point for those with salinities above 24.7 psu (Fig. 2). This affects thermal convection in the following manner. When $\mathrm{S}<24.7$ psu (brackish water), the water cools until it reaches maximum density. When the surface water becomes lighter (i.e. after the density maximum has been surpassed), cooling is restricted to the wind-mixed layer which eventually freezes over. Deep basins are filled with water of maximum density. If $\mathrm{S}>24.7$ (salt water), convection always affects the entire water body and thus cooling is slowed because of the large amount of heat able to be
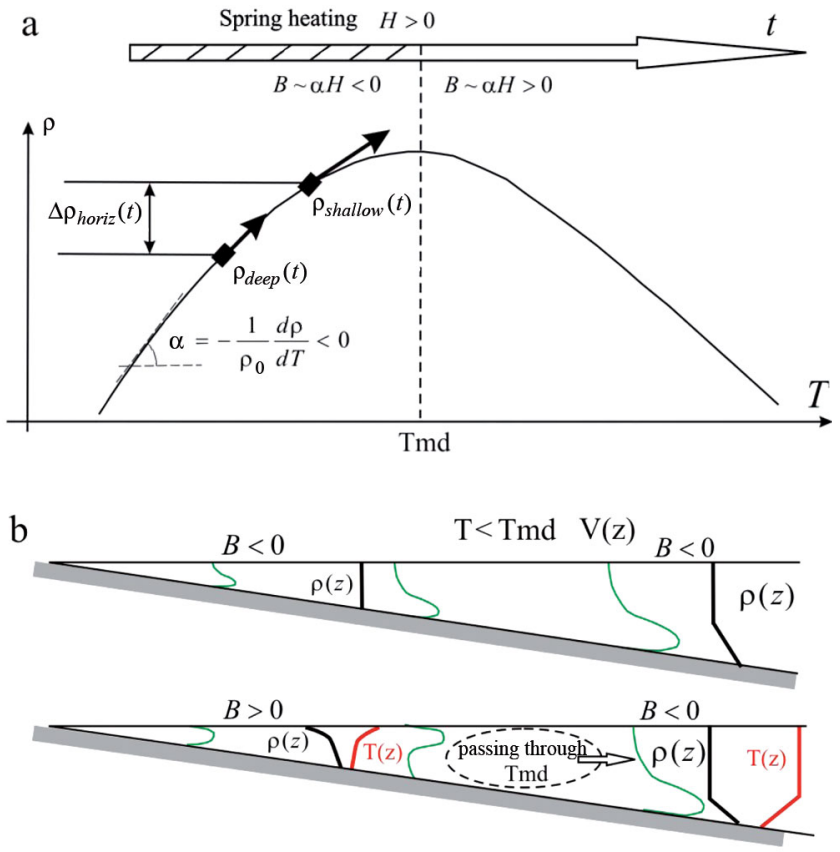

Fig. 1. (a) Variation in water density with temperature when passing through the Tmd during spring heating. Physically, the change of the vertical mixing regime at $\mathrm{T}=\mathrm{Tm}$ is due to the change from a negative to a positive buoyancy flux $(\mathrm{B}<0$ or $\mathrm{B}>0$, respectively) in the surface layer. The period during which vertical convection is maintained (or $\mathrm{B}<0$ ) is marked by hatching $(H$ : heat flux; $\alpha$ : thermal expansion coefficientsee equation under curve). The rectangles that move with time along the curve $\rho(\mathrm{T})$ illustrate the character of the density variations in both the near-shore zone $\left(\rho_{\text {shallow }}(t)\right)$ and deepwater zones $\left(\rho_{\text {deep }}(t)\right)$ under the conditions of spring heating which leads to the formation of a large horizontal density gradient $\left(\Delta \rho_{\text {horiz }}(t)\right)$. (b) Vertical temperature (red), density (black) and velocity (green) profiles of a basin with a sloping bottom, before (top) and during (bottom) the transition to the Tmd. The Tmd marks the boundary between regions of stable and unstable vertical thermal stratification, with the latter advancing offshore with duration of heating

stored in the water body (due to the water reaching freezing point before maximum density is attained). This means that one may also expect the formation of thermal bar-like fronts in the Baltic Sea (whose upper layer has a salinity ranging from 3 to 12 psu and a Tmd from 3.3 to $2.3^{\circ} \mathrm{C}$ ).

Despite there being physical evidence of the process of transition of water temperature across the Tmd in the brackish waters of the Baltic Sea, the process has up until now been very poorly investigated (Viktorov \& Losinsky 1985, Bychkova et al. 1987).

The main goal of the present paper is to reveal (1) whether a high-gradient zone (i.e. thermal front) associated with the Tmd appears in the Baltic Sea; (2) the specific features of the propagation of the thermal front in the Baltic; (3) the natural inter-annual variability of the characteristics of the seasonal structural front in the Baltic. 


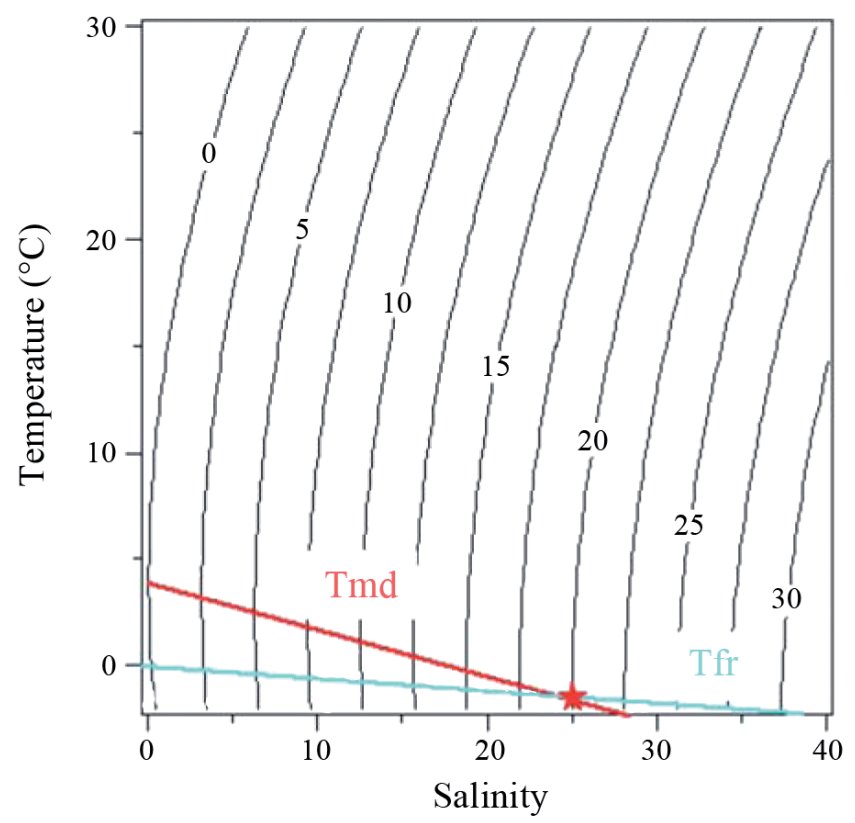

Fig. 2. Isolines of specific density $\left(\mathrm{kg} \mathrm{m}^{-3}\right)$ of salt water plotted in temperature-salinity axes. The lines represent the temperatures of maximum density (red, Tmd) and freezing (blue, Tfr). Since both of these decrease with increasing salinity, waters with salinities of $\mathrm{S}<27.4$ psu reach their maximum density in the liquid phase. In the temperature range $\mathrm{Tfr}<\mathrm{T}<$ Tmd these waters exhibit abnormal behavior: their density increases with rising temperature. This causes an abnormal response of the water column to heat fluxes through its surface: heating leads to vertical convection, while cooling results in stratification

The paper is organized as follows: Section 2 contains a description of materials and methods used, while Section 3 contains an analysis of the long-term monthly mean SST data for the Baltic Sea (taken from Janssen et al. 1999). In Section 4, data regarding the specific springs of 2003 (after a severe winter) and 2007 (after a mild winter) are examined, with a discussion and overall conclusions presented in Sections 5 and 6.

\section{MATERIALS AND METHODS}

In order to determine the general background characteristics of the spring transition of water temperature over the Tmd in the Baltic Sea, the following data were employed:

(1) Long-term monthly mean SST data from the database of the Leibniz Institute for Baltic Sea Research in Warnemünde (Institut für Ostseeforschung Warnemünde, hereafter IOW). The database contains 3.1 million temperature samples and 2.5 million salinity samples, collected in the Baltic and North Seas during the period from 1900 to 1996 and averaged over a $10 \times$ $10 \mathrm{~km}$ horizontal grid and 18 vertical layers (for further details see Janssen et al. 1999). Climatological data were obtained from the databases of a number of international and national institutions, namely ICES (International Council of the Exploration of the Sea) Oceanographic Data Center and the German national DOD (Deutsches Ozeanographisches Datenzentrum, German Oceanographic Data Center). Temperature and salinity data for the period 1900-1996 were requested from these organizations for the region from $4^{\circ}$ to $31^{\circ} \mathrm{W}$ and from $47^{\circ}$ to $66^{\circ} \mathrm{N}$, an area covered by around 500000 single stations. In terms of data distribution, the vertical structure of the gridded data set is composed of 18 layers with boundaries at the following depths: every $10 \mathrm{~m}$ from 0 to $100 \mathrm{~m}$, then at 125, 150, $200,250,300,400,500$ and $1000 \mathrm{~m}$. The result of this choice of horizontal and vertical grid spacing is a matrix of 207 (longitude) × 177 (latitude) $\times 18$ (depth) grid points. The planned use of the gridded data set as an initialization and validation field for the numerical models makes it necessary to fill all grid cells, with the 'Delauney Triangulation' (Isaaks \& Srivastava 1988) interpolation scheme with the highest efficiency used for this purpose. For the correct interpretation of a filled climatological mean data set, special smoothing is required. In order to obtain the required information regarding correlation scales, several omni-directional and directional semi-variograms (Deutsch \& Journel 1998) were computed and carefully examined.

(2) Field measurement data obtained by the IOW as part of the framework of the HELCOM program, along a section of the southern and central Baltic during the springs of 2003 and 2007 (21 to 31 March and 2 to 12 May 2003; 23 March to 1 April and 4 to 12 May 2007).

(3) Satellite data gathered by the Advanced Very High Resolution Radiometer operating onboard the weather satellite series of the US National Oceanic and Atmospheric Administration (NOAA). Full resolution data (Local Area Coverage, LAC) are directly transferred in high resolution transmission mode (HRPT) to any receiving station when the antenna follows the satellite, with the LAC data stored as long as the satellite is passing a NOAA/NASA receiving station. The third method involves a Global Area Coverage (GAC) mode in which data are reduced to $4 \mathrm{~km}$ resolution. The German Federal Maritime and Hydrographic Agency (Bundesamt für Seeschifffahrt und Hydrographie Hamburg) operates a Sea-Space - HRPT (High Resolution Picture Transmission) receiving station and uses the image processing system TeraScan. The station receives the LAC data directly from the satellite when it passes over Europe. After reception, the data are then processed and SST maps derived using TeraScan. Two general types of NOAA standard algorithms are implemented in order to calculate actual sea surface temperatures; we used the multichannel SST lin- 
ear split window algorithm. Weekly mean SST images were calculated on the basis of all cloud-free pixels of the available scenes (overpasses) during each week (Siegel et al. 2008).

(4) Subsurface water temperature, salinity and chlorophyll a measurements performed by the Finnish Institute of Marine Research (Ship of Opportunity program) along the ferry route between Travemünde and Helsinki during the following periods: 16 to 18 March; 5 to 7 April; 26 to 28 April and 4 to 6 May 2003. The following method was employed: water was pumped constantly through the sensors at a fixed depth (ca. $5 \mathrm{~m}$ ) while the ship was moving, with in vivo chlorophyll a and phycocyanin fluorescences, temperature and salinity recorded quasi-continuously at a spatial resolution of 100 to $200 \mathrm{~m}$. Once in harbor, the devices were automatically washed using the Triton-X detergent system. Measurement and sampling was repeated ca. every 0.5 to $3 \mathrm{~d}$ in the same area, depending on the schedule of the ferry. This was controlled through the use of the Ferrybox monitoring software, located in the electronics box. In addition, every week on 1 transect, 12 to 24 water samples were taken. Sampling and analyses were quality controlled using ISO GUIDE 25 and SFS-EN 45001, while laboratory methods were also of accredited standard.

\section{RESULTS}

\subsection{Seasonal transition of SST over the Tmd}

Before outlining the particular features of the frontal zone associated with the Tmd in the Baltic, it is first necessary to describe the general background of its existence, i.e. where, when and how the transition over the Tmd occurs in terms of Baltic long-term monthly mean SSTs. In order to be able to classify a particular area as a thermal frontal zone, it is also necessary to first define the large-scale mean horizontal temperature gradient required for the formation of such fronts.

The most regular and gentle underwater slopes in the Baltic (i.e. those providing the most favorable conditions for large-scale temperature gradient formation; Kahru et al. 1995) are located along the southern (from Rügen island to the Hel peninsula) and eastern coasts (from the Gulf of Finland to the Sambian peninsula) (Seifert et al. 2001).

Analysis of long-term monthly mean SST data for spring (Janssen et al. 1999) reveals that waters characterized by temperature values of $\mathrm{T} \approx$ Tmd first arise in mid-March near the southern and eastern coasts (Tmd $\sim 2.3$ to $2.5^{\circ} \mathrm{C}$, salinity $\mathrm{S} \approx 7$ to $8 \mathrm{psu}$ ). Over time this region of $\mathrm{T} \approx$ Tmd waters shifts towards the island of Gotland. By mid-April, SSTs are already above the
Tmd in both the Arkona basin and in eastern and southern parts of the Gotland basin, with the Tmd region lying approximately along the meridian $56^{\circ} \mathrm{N}$ (at $\mathrm{S} \approx 7.3$ to $7.6 \mathrm{psu}$ ), as well appearing along the northern shores of Gotland (Fig. 3b). By mid-May, the region of $\mathrm{T} \approx \mathrm{Tm}$ has spread to the mouth of the Bay of Bothnia ( $\mathrm{Tmd} \approx 3^{\circ} \mathrm{C}, \mathrm{S} \approx 4.5 \mathrm{psu}$ ). Analysis of these SST data also enables an estimation to be made of the average speed of the northward advancement of the $\mathrm{T} \approx$ Tmd region, of around 300 to $500 \mathrm{~km} \mathrm{mo}^{-1}$ or 11 to $16 \mathrm{~km} \mathrm{~d}^{-1}$. This value is well above the upper limit of the velocities reported in freshwater lakes, for which a maximum speed of thermal bar propagation of around $6 \mathrm{~km} \mathrm{~d}^{-1}$ has been estimated (Korosov et al. 2006). A similar pattern is confirmed by mean-annual temperature variations derived from analysis of satellite images (Siegel et al. 2008). Southern and eastern parts of the Baltic Sea are the first to warm up, with the region of surface water temperatures higher than the Tmd for the given salinity occurring here. This region then migrates to the Gotland basin in April, shallow areas of the Bothnian Sea in May and finally the Bay of Bothnia by mid-June.

Analysis of long-term monthly mean temperature data enables the estimation of a large-scale long-term monthly mean horizontal temperature gradient. Calculated for the distance of ca. $950 \mathrm{~km}$ between the Arkona basin and the northern Gulf of Finland, this gradient is in the order of around $10^{-6 \circ} \mathrm{C} \mathrm{m}^{-1}$ during spring. Thus any region characterized by a horizontal temperature gradient exceeding $10^{-5 \circ} \mathrm{C} \mathrm{m}^{-1}$ can ostensibly be considered a sea-scale frontal zone.

\subsection{Annual variation in the spring transition process}

Having described the general features of Baltic water temperature transition across the Tmd, we shall now turn towards an analysis of vertical thermohaline structure and its variability from year to year as observed in recent field measurement data. Such data are available for central and eastern parts of the Baltic Sea thanks to the standard monitoring procedure carried out since 2001 by the IOW as part of the framework of the HELCOM Program (monitoring reports can be accessed online at www.io-warnemuende.de/cruisereports.html). This study concentrates on the spring transition period only, with hydro-physical data from 8 expeditions examined.

In order to obtain more detailed information, 2 particular spring periods - 2003 and 2007 - were selected from the data obtained by the IOW monitoring expeditions, since these springs were followed by 2 winters of highly contrasting severity. Data of 4 cruises are collected in the cruise reports: no. 11/03/02 (www.io- 
Temperature

$\left({ }^{\circ} \mathrm{C}\right)$
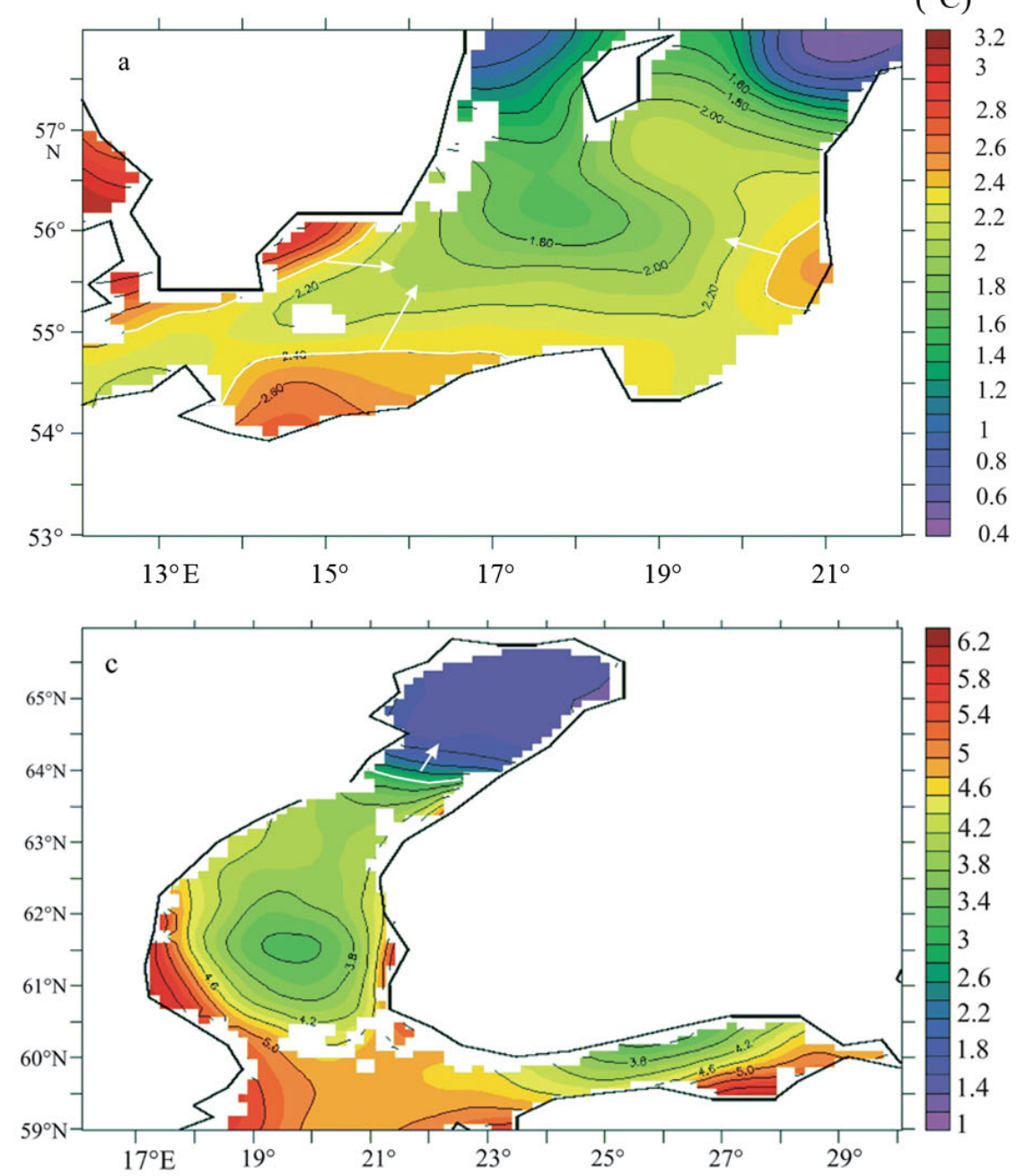

Temperature

$\left({ }^{\circ} \mathrm{C}\right)$

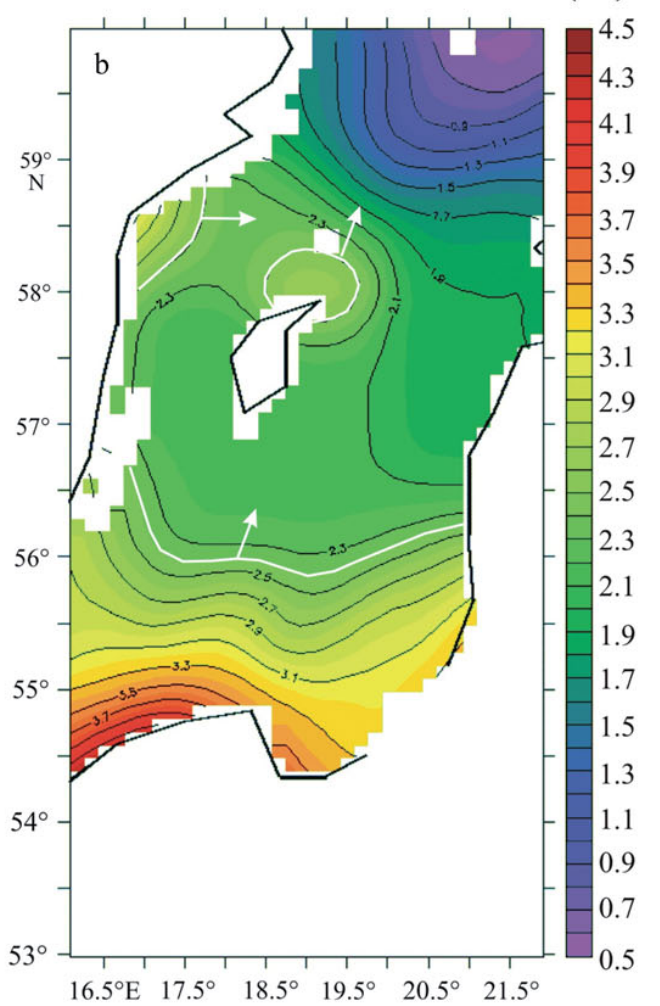

Fig. 3. Spring warming of the Baltic Sea based on long-term monthly mean data for (a) March, (b) April and (c) May (Janssen et al. 1999). The white lines show the location of areas where water temperatures are close to the Tmd (the presence of which depends on local water salinity), with the arrows indicating the advancement of these areas over time from south to north and from shallow to deeper regions

warnemuende.de/tl_files/forschung/pdf/cruise-reports/ cr110302.pdf), no. 44/03/03 (www.io-warnemuende.de/ tl_files/forschung/pdf/cruise-reports/cr440303.pdf), no. 07PE/07/07 (www.io-warnemuende.de/tl_files/forschung/ pdf/cruise-reports/cr400707.pdf) and no. 07/PE/07/10 (www.io-warnemuende.de/tl_files/forschung/pdf/cruisereports/cr400710.pdf).

\subsection{Thermal front after a relatively severe winter (2002-2003)}

The winter of 2002-2003 was the most severe since 1995-1996, and the second most severe (after 19861987) of the last $30 \mathrm{yr}$ (www.bsh.de). After an extremely cold December 2002, water temperatures in the central and northern Baltic Sea in January were well below the typical average, and also below the Tmd. However, March conditions were warmer than usual, and air temperature during May in the central and northern Baltic was $>2{ }^{\circ} \mathrm{C}$ higher than the mean annual value (data from www.bsh.de). Such conditions were likely extremely favorable for structural front formation since they suggest the presence of a large horizontal temperature gradient.

\subsubsection{Vertical temperature and salinity cross sections at Tmd}

Between 21 and 28 March 2003 (Feistel 2003, Fig. 4a), the upper freshened layer had a temperature below 

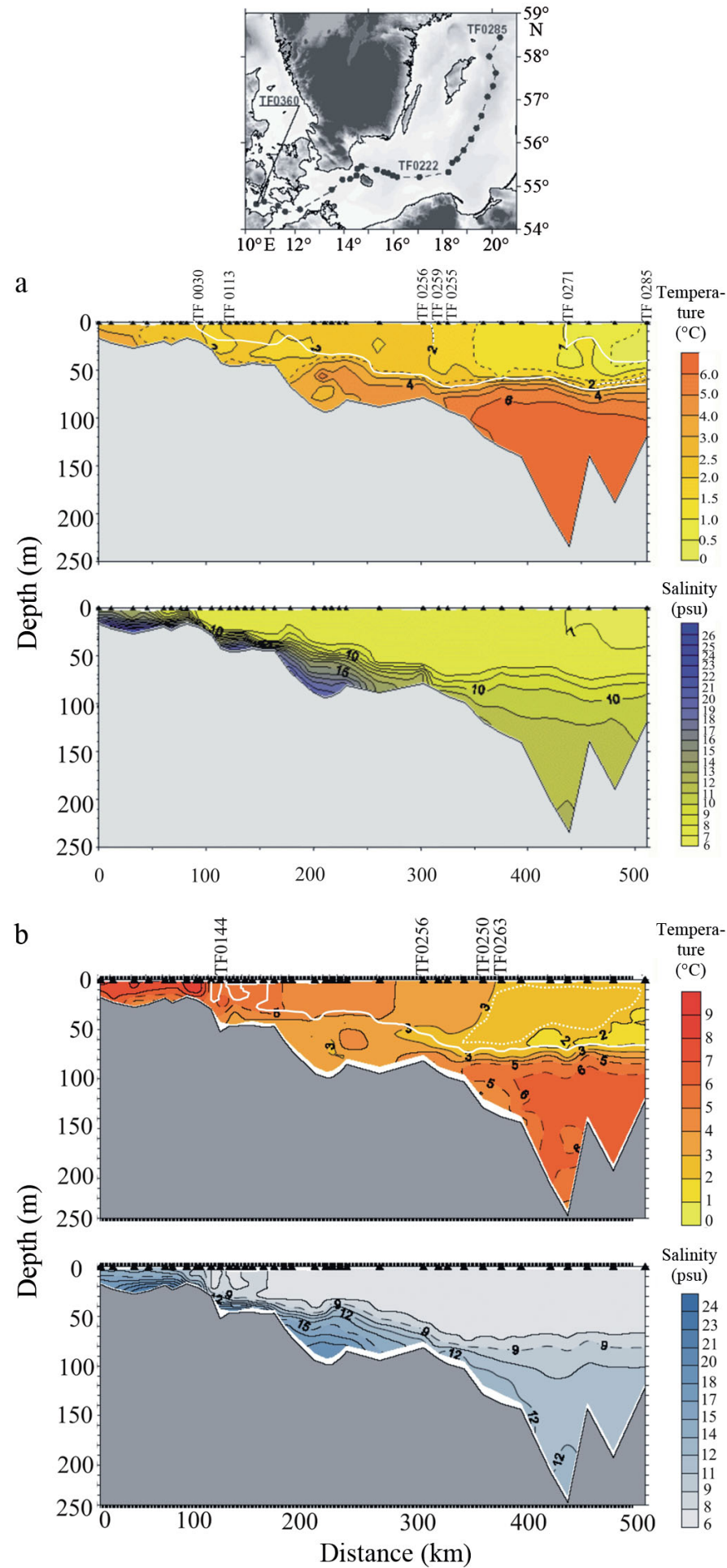

Fig. 4. Temperature and salinity cross-sections constructed using IOW monitoring data (www.io-warnemuende.de) taken during the periods (a) 21-28 March 2003 (Feistel 2003); and (b) 2-7 May 2003 (Nausch 2007) in the western and central Baltic. The white lines in the temperature cross-sections represent the lower boundary of the freshened homogeneous layer (taken from salinity data). The dotted white lines indicate the position of the Tmd (depending on salinity). The location of the section is indicated above Panel (a) the Tmd along its entire cross-section (with small variations), with its thickness of about $70 \mathrm{~m}$ in the central Baltic delineated by an 8 psu isohaline at its lower boundary. The northern part of the cross-section is characterized by an inverse vertical temperature stratification. In the central region (TF 0256 and TF 0259; Fig. 4a), the upper layer is homogenized at 2 to $2.5^{\circ} \mathrm{C}$ down to a depth of around $50 \mathrm{~m}$, with a slightly warmer layer below (but above the pycnocline).

Between 2 and 7 May 2003 (Nausch 2003), the salinity of the study area exhibited almost the same structure (Fig. 4b), with the 65 to $70 \mathrm{~m}$ thick upper freshened layer again delineated by an 8 psu isohaline. The temperature cross-section diagram displays the beginning of the formation of direct summer stratification in the southern part of the section (from TF 0144 to TF 0256; Fig. 4b), with water temperatures above the Tmd. The northern part of the section is characterized by water temperatures close to the Tmd. Isotherms in the upper $(40 \mathrm{~m})$ layer are generally S-shaped, and tilted northwards in their upper-most part. Such a configuration is a typical manifestation of the 'fast stage' of thermal bar development (Kreiman 1989).

Additional information is provided by the satellite SST images, in which the structure of the temperature field on the surface of the Baltic can be observed during the corresponding dates. The image taken on 24 March (Fig. 5a) reveals the presence of a region with a relatively high horizontal temperature gradient located in the southern part of the Baltic, near station TF 0255, with water temperatures elsewhere in the Baltic proper still below the Tmd. On 8 May (Fig. 5b), surface temperatures in southern and central parts of the Baltic were already above the Tmd (at around 7 to $8^{\circ} \mathrm{C}$ and $5^{\circ} \mathrm{C}$, respectively), while those in the Bothnian Sea were around the Tmd or slightly below.

\subsubsection{Surface temperature measurements across the Tmd}

To complement the picture described in the previous section, we also examined surface temperature measurements (performed by the Finnish Institute of Marine Research, now renamed the Finnish Environmental Institute) along the Travemünde-Helsinki ferry route during spring.

These measurements (Fig. 6) illustrate that an obvious temperature jump is always associated with the area in which water temperatures cross the Tmd threshold (i.e. the central and northern Baltic). During the onset of the heating process, the horizontal temperature gradient in this area is around $2 \times 10^{-5}{ }^{\circ} \mathrm{C} \mathrm{m}^{-1}$, a value 20 times larger than the long-term monthly mean horizontal temperature gradient (calculated in Section 2.1), and thus this area can be classified as a frontal zone. In the middle of the 
a

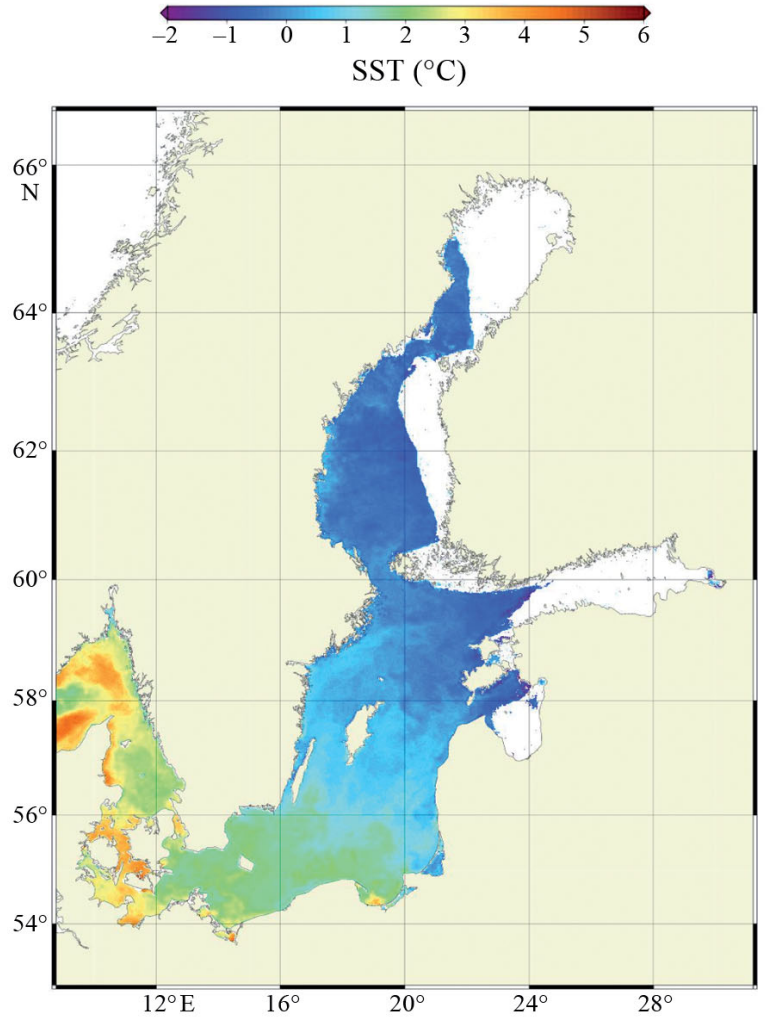

b
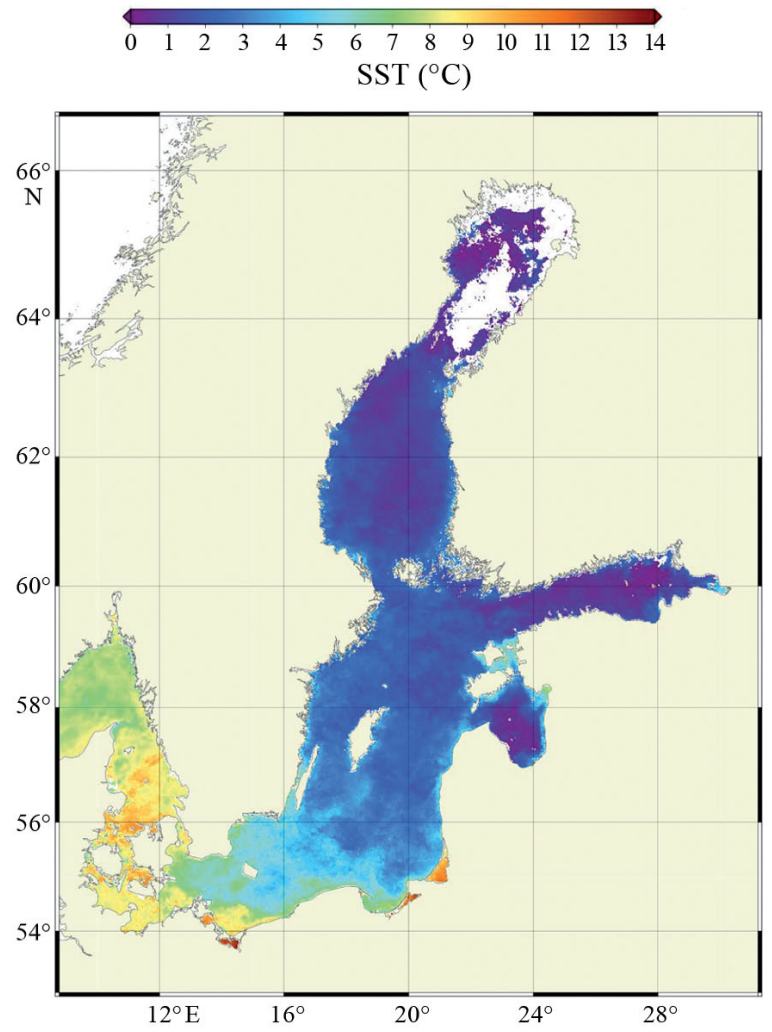

Fig. 5. Weekly composite SST images of the Baltic Sea from (a) 22-28 March; (b) 2-8 May 2003 (courtesy of the Bundesamt für Seeschifffahrt und Hydrographie). Note that temperature scales differ between panels
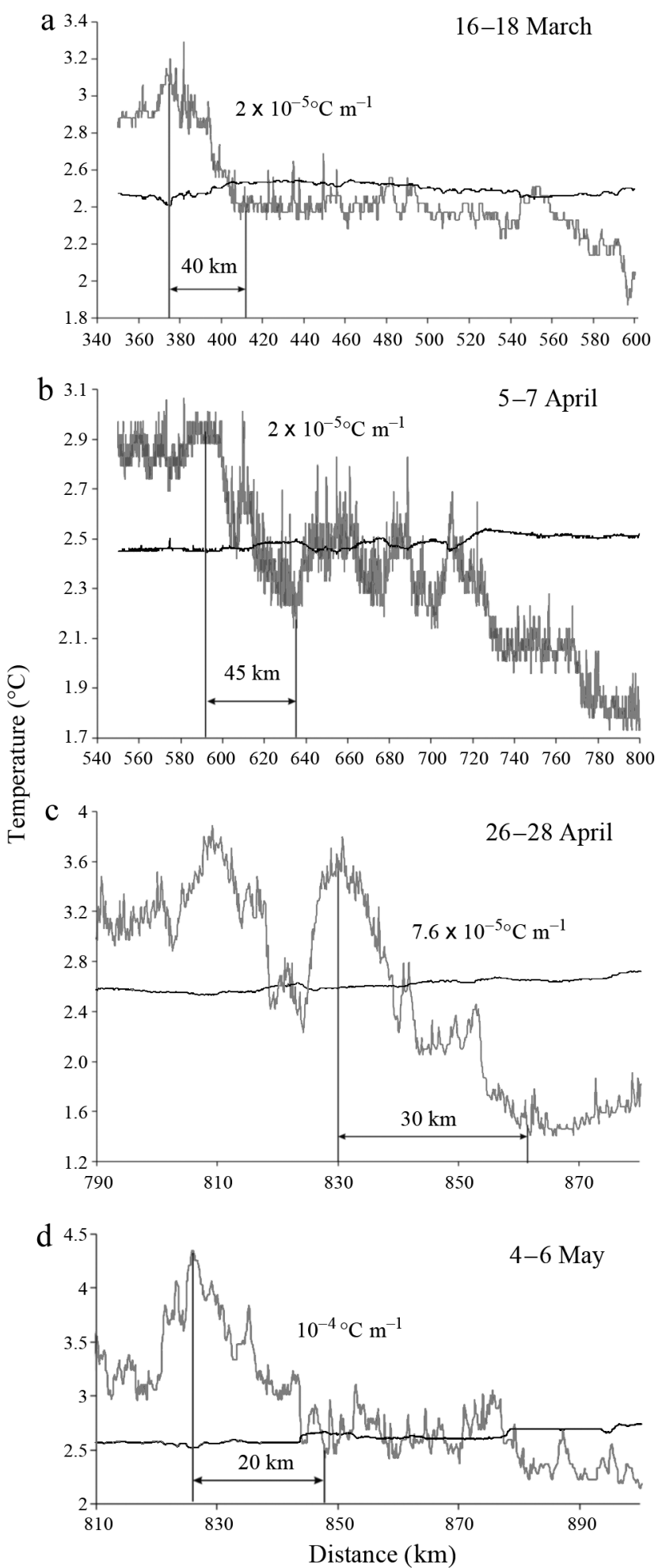

Fig. 6. Data illustrating a frontal jump in the vicinity of the Tmd (line ranging from 2.3 to $2.6^{\circ} \mathrm{C}$ on $y$-axes), occurring along the Travemünde-Helsinki ferry route, obtained during the periods (a) 16-18 Marchi (b) 5-7 April; (c) 26-28 April; (d) 4-6 May. Values of the horizontal temperature gradient in the frontal zone and widths of the frontal zone are shown in the graphs. Data: Finnish Institute of Marine Research 
spring period, the horizontal temperature gradient of this frontal zone increases further (almost quadrupling), and by the end of the heating process the gradient $\left(10^{-4}{ }^{\circ} \mathrm{C}\right.$ $\mathrm{m}^{-1}$ ) is 100 times larger than the long-term monthly mean equivalent. Temperature differences across the frontal zone are in the range of 1.5 to $2^{\circ} \mathrm{C}$. At the beginning of the process, the width of the frontal zone is around $45 \mathrm{~km}$; by the end this decreases to $20 \mathrm{~km}$. For comparison, the horizontal temperature gradient of the frontal zone in Lake Ladoga at the end of the heating period is around $4.5 \times 10^{-3}{ }^{\circ} \mathrm{C} \mathrm{m}^{-1}$ (Naumenko 1989), a value 45 times larger than the horizontal temperature gradient of the Baltic frontal zone. Temperature differences across the lake frontal zone are 4 to $4.5^{\circ} \mathrm{C}$, around 2.5 times greater than those of the Baltic frontal zone. Lacustrine thermal bar fronts therefore tend to be much sharper.

The speed of frontal zone propagation across the surface of the Baltic Sea slightly increases with time of heating, from around $11 \mathrm{~km} \mathrm{~d}^{-1}$ at the onset of warming to $11.4 \mathrm{~km} \mathrm{~d}^{-1}$ by the end of the process. These values are twice as large as those typically observed in lakes (Korosov et al. 2006, Naumenko \& Karetnikov 1998), with only the speed of propagation of the Tmd-isotherm in Lake Ontario anywhere close at around $11 \mathrm{~km} \mathrm{~d}^{-1}$ (Rodgers 1966). This rapidity is probably the result of salinity, since the value of the Tmd increases with decreasing salinity from south (Tmd $=2.3$ to $2.5^{\circ} \mathrm{C}$ for $\mathrm{S}=$ 7 to $8 \mathrm{psu}$ ) to north ( $\mathrm{Tmd}=3^{\circ} \mathrm{C}$ for $\mathrm{S}=4.5 \mathrm{psu}$ ).

Measurements taken on 18-20 March (Fig. 7a) reveal an extended area of high chlorophyll a concentrations in waters of temperature close to the Tmd (in the central Baltic), with levels increasing in the frontal zone to 18 to $20 \mathrm{mg} \mathrm{m}^{-3}$, values roughly 9 times greater than those in the southern Baltic (with the exception of southern coasts near the Danish Straits). With a width of around $200 \mathrm{~km}$, the zone of high chlorophyll a concentrations advances northwards together with the thermal front. By 4-6 May, the amount of chlorophyll a had increased to 12 to $13 \mathrm{mg} \mathrm{m}^{-3}$ in the frontal zone (Fig. $7 \mathrm{~b}$ ), levels roughly 6 times as large as those in the southern and central Baltic (except the Gulf of Finland).

\subsection{Thermal front after a relatively mild winter (2006-2007)}

The winter of 2006-2007 was both mild and short (www.bsh.de), and according to the 'cold sum' of winter air temperatures in Warnemünde was the mildest since records began in 1948. Indeed, the 2006-2007 'cold sum' was only $10 \%$ of the 60 -yr long-term mean, warmer than the mild winters of 1999-2000 and 19891990. The months of January to April were extremely warm, with only October somewhat cooler than usual (www.bsh.de).

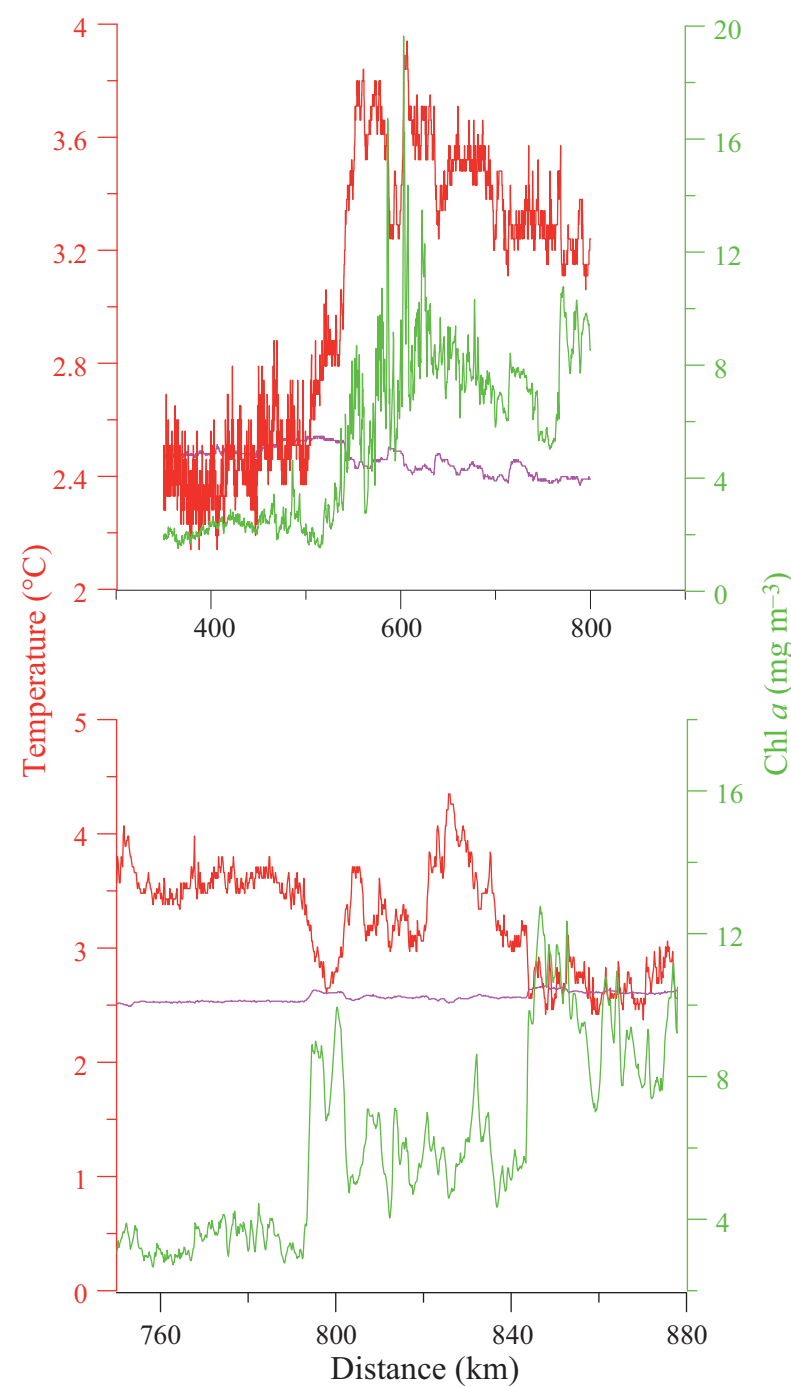

Fig. 7. Variation in chlorophyll a (green), water temperature (red) and the Tmd (purple) between Travemünde and Helsinki on 18 to 20 March (above) and 4-6 May (below) 2003. Respective temperature and chlorophyll a troughs and peaks associated with the Tmd are well-pronounced. Data: Finnish Institute of Marine Research

Data from 2 cruises, no. 07/PE/07/07 (Feistel 2007) and no. 07/PE/07/10 (Nausch 2007) performed during spring 2007 in the western and central Baltic, were available for analysis. The first cruise was carried out under calm to moderate wind conditions (Feistel 2007), while during the second, the weather was sunny with wind speeds generally low at mostly 2 to $3 \mathrm{Bft}$, only occasionally increasing to 4 Bft (Nausch 2007).

\subsubsection{Structure of temperature and salinity fields}

Analysis of thermohaline field data obtained between 23 March and 1 April 2007 during cruise no. 07/PE/07/10 

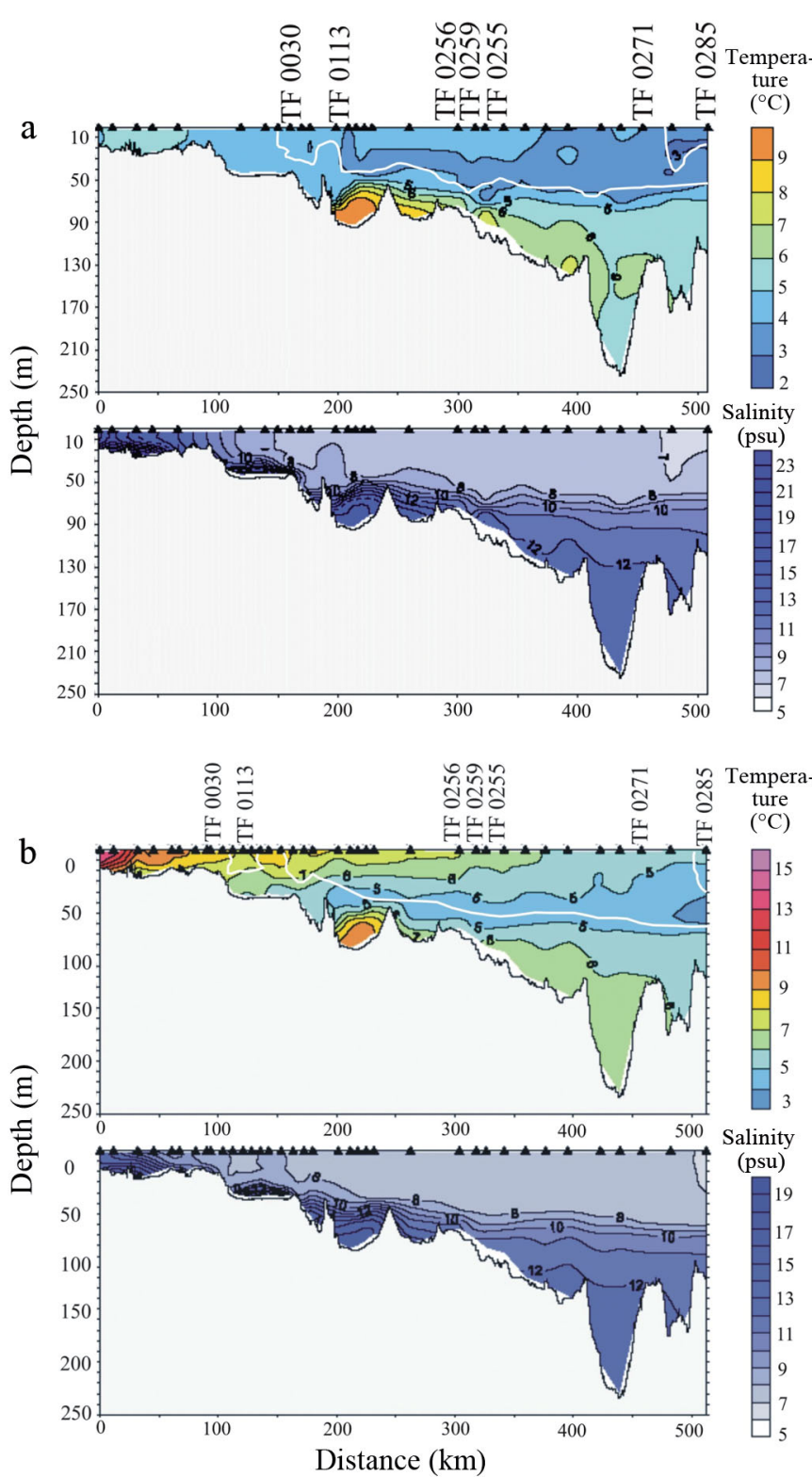

Fig. 8. Cross-sections of water temperature and salinity of the western and central Baltic, obtained during the periods (a) 23 March - 1 April 2007 (Feistel 2007); and (b) 4-12 May 2007 (Nausch 2007) (www.io-warnemuende.de). White lines on the upper panels of both (a) and (b) indicate the lower limit of the freshened quasi-homogeneous layer. These data illustrate the situation occurring after a mild winter (cf. after the severe winter of 2002-2003; Fig. 5)

(www.io-warnemuende.de/tl_files/forschung/pdf/cruisereports/cr400710.pdf; Fig. 8a) reveals the presence of the upper freshened homogeneous layer at station TF 0145 extending to a depth of $70 \mathrm{~m}$ in the central Baltic, the same pattern observed after the 2 cruises carried out in 2003. The 8 psu isohaline represents the lower boundary of the quasi-homogeneous layer. Haline structure is not homogeneous near stations TF 0285 to

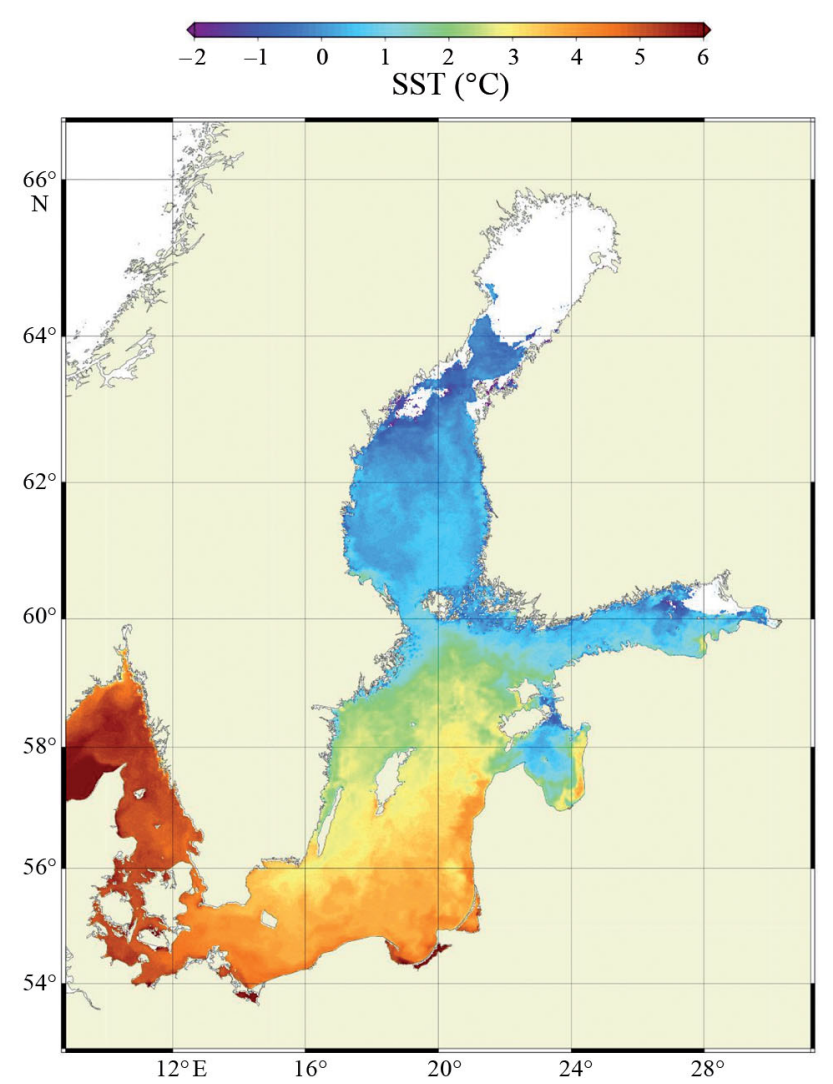

Fig. 9. Weekly composite SST image of the Baltic Sea during the period 23-29 March 2007 (courtesy of the Bundesamt für Seeschifffahrt und Hydrographie)

0286, with salinities here around 7 psu down to a depth of ca. $50 \mathrm{~m}$.

Surface water temperatures in the entire cross-sectional area are 1.7 to $2.5^{\circ} \mathrm{C}$ higher than those obtained after cruise no. 11/03/02 (www.io-warnemuende.de/ tl_files/forschung/pdf/cruise-reports/cr110302.pdf), with direct summer temperature stratification already established. Waters of temperature close to the Tmd are not found within the section. The $4^{\circ} \mathrm{C}$ isotherm is tilted towards the Gotland basin, while the $3^{\circ} \mathrm{C}$ isotherm can be observed at $30 \mathrm{~m}$ depth in the northern part of the section.

Measurements performed between 4 to12 May 2007 during cruise no. 11/03/02 (www.io-warnemuende. de/tl_files/forschung/pdf/cruise-reports/cr110302.pdf; Fig. $8 \mathrm{~b}$ ) indicate that the upper freshened layer can be delineated by the 8 psu isohaline, and has a thickness of around 65 to $70 \mathrm{~m}$. Surface water temperatures near station TF 0263 (see Fig. 9b) are around $6^{\circ} \mathrm{C}, 3^{\circ} \mathrm{C}$ higher than those observed for the same time and location during cruise no. 44/03/03 (www.io-warnemuende. de/tl_files/forschung/pdf/cruise-reports/cr440303.pdf) (Nausch 2007). In the southern part of the section, the isotherms are tilted in the upper layer towards the 

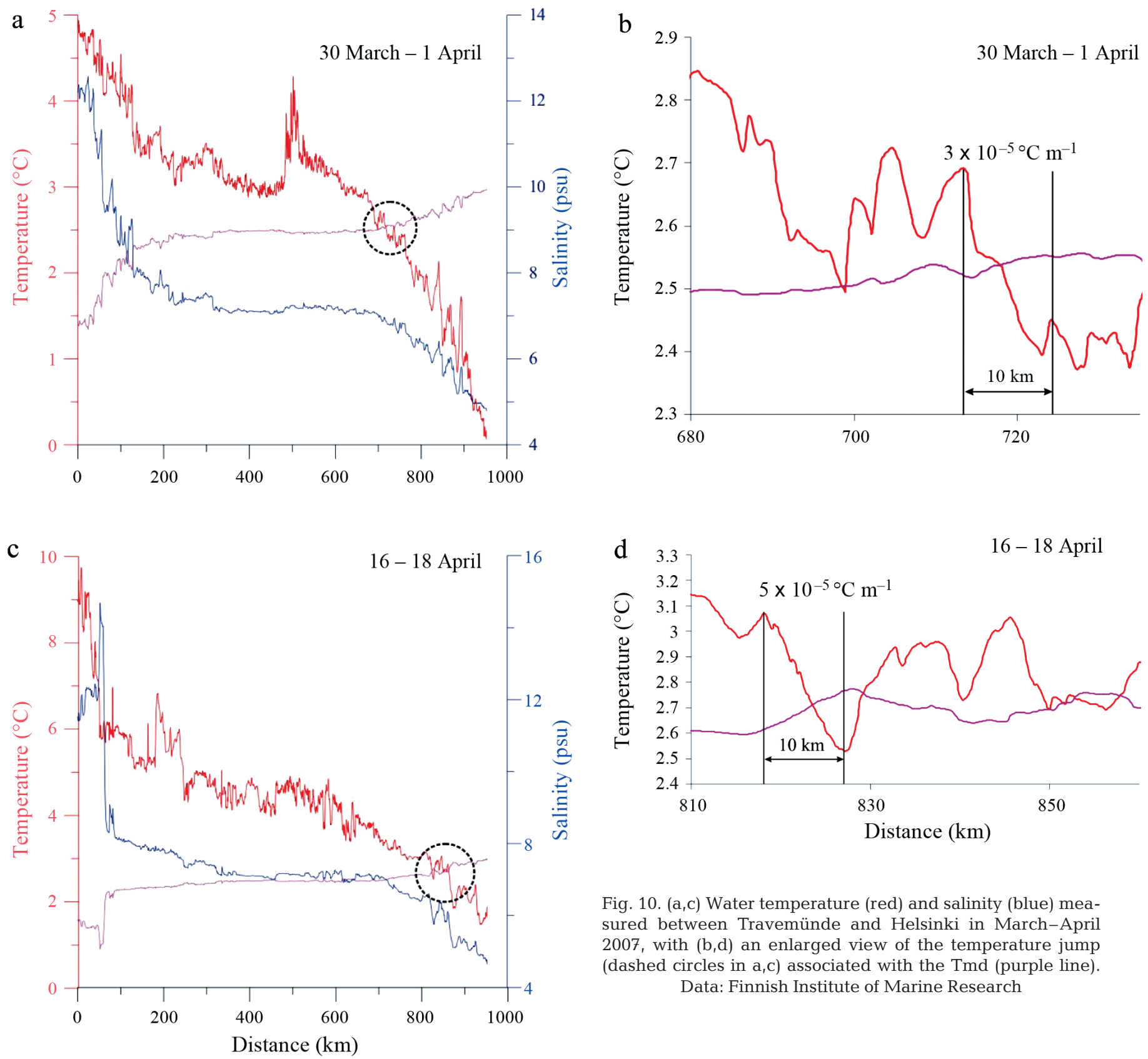

Fig. 10. $(\mathrm{a}, \mathrm{c})$ Water temperature (red) and salinity (blue) measured between Travemünde and Helsinki in March-April 2007, with (b,d) an enlarged view of the temperature jump (dashed circles in $\mathrm{a}, \mathrm{c}$ ) associated with the Tmd (purple line). Data: Finnish Institute of Marine Research

Central Gotland basin, with the $3^{\circ} \mathrm{C}$ isotherm lying at depths down to $70 \mathrm{~m}$.

The satellite image taken on 29 March 2007 (Fig. 9) reveals water temperatures in the Gulf of Finland and Bothnian Sea to be still below the Tmd, while those near the mouth of the Gulf of Finland were close to the Tmd (indeed, on 24 March 2003 such a region was found in the southern part of the gulf).

Thus after the mild winter, direct summer stratification was established 1 mo earlier in the western and central Baltic Sea, with surface temperatures up to 1.7 to $3^{\circ} \mathrm{C}$ higher than those observed after the severe winter.

\subsubsection{Surface temperature measurements across the Tmd}

Even after the very mild winter of 2006-2007, water temperatures in northern parts of the Baltic Sea were below the Tmd. Analysis of surface temperature data obtained on 1 and 18 April 2007 has enabled the identification of the location and characteristics of the region with water temperatures of $\mathrm{T} \approx$ Tmd (between the mouth of the Gulf of Finland and the Aaland islands).

Analysis of surface water temperatures also reveals the presence in 2007 of a marked temperature jump in the vicinity of the Tmd region (Fig. 10a,c). At the 


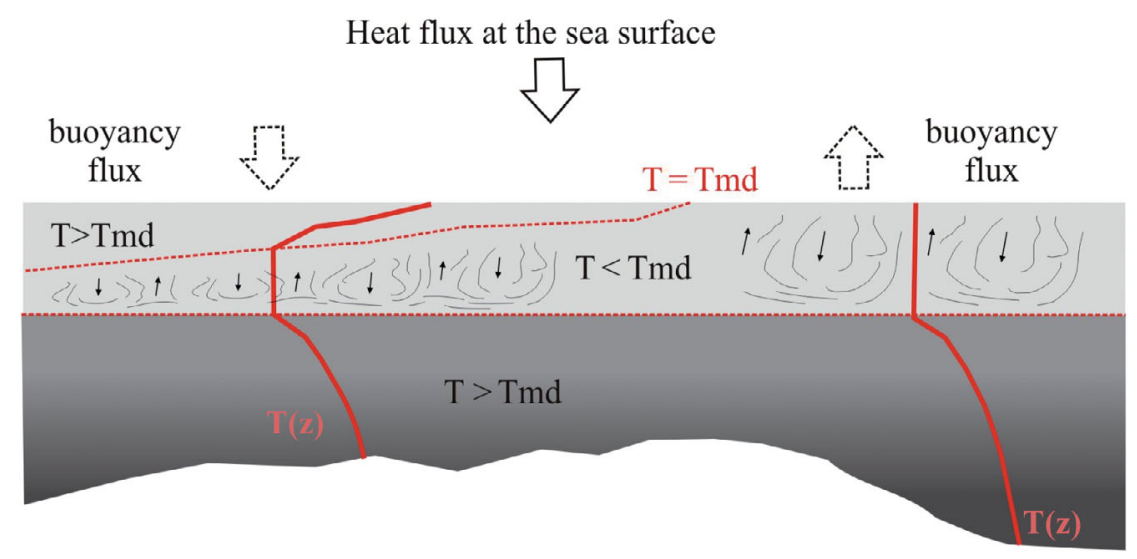

Fig. 11. Sketch of the Baltic Sea thermal bar during the spring period. Water in the lower layer (dark shading) maintains a temperature above the Tmd throughout the year, with seasonal variations of heat flux at the sea surface causing a transition across the Tmd in only the upper 40 to $80 \mathrm{~m}$. During the transition period, the same heating conditions at the sea surface cause destabilizing buoyancy flux (and vertical mixing) in one part of the basin (where $\mathrm{T}<\mathrm{Tmd}$ ) and stabilizing buoyancy flux (and strengthening of thermal stratification) in the other (where $\mathrm{T}>\mathrm{Tmd}$ )

beginning of April, the horizontal temperature gradient in this area was around $3 \times 10^{-5}{ }^{\circ} \mathrm{C} \mathrm{m}^{-1}, 30$ times larger than the long-term monthly mean gradient. By the end of the heating process up to the Tmd (midApril), the horizontal temperature gradient was around $5 \times 10^{-5}{ }^{\circ} \mathrm{C} \mathrm{m}^{-1}, 50$ times larger than the long-term monthly mean equivalent (Fig. 10b,d). Temperature differences across the frontal zone were only around $0.5^{\circ} \mathrm{C}$, with the width of the frontal zone area where the temperature jump took place at $\sim 10 \mathrm{~km}$.

Thus it can be seen, that even though after the mild winter the temperature difference across the thermal front was smaller and the width of the frontal zone 4 to 5 times lower than that observed after the relatively severe winter, the region with water temperatures of $\mathrm{T} \approx$ Tmd maintains certain features characteristic of a frontal zone.

\section{DISCUSSION}

The Baltic Sea exhibits 2 layers of salinity stratification, consisting of an upper freshened layer (down to a depth of $70 \mathrm{~m}$ in the Baltic proper) that is almost homogeneous in terms of salinity, and a more salty deep layer below the permanent pycno(halo)cline. The previously described freshwater exchange process is applicable only to the upper layer, with the halocline playing the role of a 'liquid bottom' (see Fig. 11). The latter's slope, a result of general sea-scale estuarine circulation, is around $10^{-4}$. As a consequence, the Baltic spring thermal front travels in exactly the same manner as the lacustrine equivalent, i.e. following the inclination of the 'liquid bottom'. While crossing the Tmd, under the same heating conditions as those on the surface, water on one side of the Tmd-isotherm is stably stratified; here the isotherms become S-shaped and tilted in the upper layer towards the cold region. In contrast, waters with temperatures on the other side of the Tmd are prone to vertical mixing; here isotherms are vertical. Thus the 'thermal bar' of a brackish basin is in effect a seasonal thermally-induced structural front (or, more succinctly, a structural front), because it may appear seasonally —in spring and fall—associated with the Tmd (for a given salinity), and is characterized by different types of mixing processes on either side of the front. In contrast to the freshwater thermal bar, the Tmd-value in brackish basins varies both horizontally and vertically, with no particular isotherm associated with the frontal division. In lakes, non-simultaneous transfer of water temperature across the Tmd (and thus formation of the front) is solely due to the influence of lake bathymetry: shallow areas react faster than deeper areas to external heat conditions. At the larger scale of the sea, horizontal differences in upper-layer salinity become significant, enabling an additional mechanism of front formation via the propagation of the Tmd along the salinity gradient in upper layers. However, even disregarding south-north differences in heat flux taking place through Baltic surface waters, one encounters a much more complex physical situation.

\section{CONCLUSIONS}

1. Joint analysis of long-term monthly mean data, contact measurements and SST satellite images clearly demonstrates that a thermal front associated with the Tmd - a direct analogue of the thermal bar in freshwater lakes - also occurs in brackish waters of the Baltic Sea. The data also reveal specific features of its development with respect to climate variability. 
2. Despite the present warming phase that began in 1970 in the Baltic Sea, the temperature anomalies of winter periods, which have been evaluated for each year from 1990 to 2005 by Siegel et al. (2008), do not reflect warming. Comparative analysis of field measurement data for different years has been able to shed some light onto the response of the Baltic structural front to winter seasons of varying severity. Horizontal temperature gradient and temperature differences across the frontal zone appear to be 2 and 4 times higher after a severe winter than after a mild winter, respectively. The width of the frontal zone, however, is of the same scale after both types of winter. The characteristic lifetime of the Baltic structural front after the mild winter was $20 \mathrm{~d}$ shorter than after the severe winters; in the former, the spring bloom in biological production ends $\sim 1$ mo earlier.

3. The speed of structural front propagation is derived from an interplay of 3 physically different factors: (1) south-north variations in incoming solar radiation, (2) bottom and pycnocline topography, and (3) significant variation of the Tmd-value due to large horizontal salinity differences (increasing in a northerly direction). Clearly the spring transition is of longer duration, on average being more pronounced than in fall (as is also commonplace in lakes, although for different reasons).

Acknowledgements. This work was financially supported by INTAS YSF grant no. 06-1000014-6508 and RFBR grants no. 10-05-00472, no. 10-05-00540 and no. 11-05-90743_mob_st. N.D. expresses great thanks to Prof. Hans Burchard and Dr. Herbert Siegel for the opportunity to work with the IOW database and satellite images of the Baltic Sea.

\section{LITERATURE CITED}

Bychkova IA, Viktorov SV, Losinsky VN (1987) Structure of coastal fronts of the Baltic Sea from remote sensing data of infra-red range. Proc 3rd Congr of Sov Oceanogr. V. III, Hydrometeoizdat, Leningrad, p 64-65

Chubarenko I, Demchenko N (2008) Laboratory modeling of the thermal bar and circulation associated with it in a basin with a sloping bottom. Oceanology (Mosc) 48:356-370

Deutsch CV, Journel AG (1998) GLIB: geostatistical software

Submitted: November 9, 2009; Accepted: July 11, 2011 library and user's guide, 2nd edn. Oxford University Press, New York, NY

Fedorov KN (1983) Physical nature and structure of oceanic fronts. Hydrometeoizdat, Leningrad

Forel FA (1901) Études thermique des lacs du nord de l'Europe. Arch Sci phys not 4(12):35-55

Isaaks E, Srivastava R (1988) An introduction to applied geostatistics. Oxford University Press, New York, NY

Janssen FC, Schrum JO, Backhaus S (1999) A climatological data set of temperature and salinity for the Baltic Sea and the North Sea. Dtsch Hydrogr Z 51(Suppl 9):5-245

Kahru M, Hakansson B, Rud O (1995) Distributions of the seasurface temperature fronts in the Baltic Sea as derived from satellite imagery. Cont Shelf Res 15:663-679

Korosov AA, Pozdnyakov DV, Filatov NN, Grassl $H$, Mazourov AA, Loupyan EA, Ionov VV (2006) A satellite data-based study of seasonal and spatial variations of some ecoparameters in Lake Ladoga. Earth Obs Remote Sens 5:76-85

Kreiman KD (1989) Thermal bar based on laboratory experiments. Oceanology 29:935-938

Naumenko MA (1989) Horizontal temperature gradients in the thermal frontal zone of large fresh lake. Meteorol \& Hydrol 6:89-94

Naumenko MA (1992) Variability of currents during the passage of the thermal bar front in Lake Ladoga. Proc AllUnion Geogr Soc 124:547-551

Naumenko MA, Karetnikov SG (1998) On a speed of propagation of the thermal front in Lake Ladoga. Meteorol \& Hydrol 4:107-115

Rodgers GK (1966) The thermal bar in Ontario, spring 1965 and winter 1965-1966. Proc 9th Conf Great Lakes Res. Publ. No. 11, Great Lakes Research Division, University of Michigan, p 369-374

Rumiantsev VA, Drabkova VG (eds) (2002) Ladoga Lake: past, present, future. Institute of Limnology of RAS, St Petersburg

Seifert T, Tauber F, Kayser B (2001) A high resolution spherical grid topography of the Baltic Sea, 2nd edn. BSSC, Stockholm. www.io-warnemuende.de/iowtopo

Shimaraev MN (ed) (1977) Thermal regime of the Baikal lake. Nauka, Irkutsk

Siegel H, Gerth M, Tschersich G (2008) Satellite-derived sea surface temperature for the period 1990-2005. In: Feistel R, Nausch G, Wasmund N (eds) State and evolution of the Baltic Sea, 1952 - 2005: a detailed 50-year survey of meteorology and climate, physics, chemistry, biology, and marine environment. John Wiley, Hoboken, NJ, p 241-265

Tikhomirov AI (1982) Thermics of large lakes. Nauka, Leningrad

Viktorov SV, Losinsky VN (1985) Complex ground-truth oceanographic experiment of USSR and GDR on the Baltic Sea. GOIN, Leningrad

Proofs received from author(s): July 18, 2011 